\title{
Capacity factors of solar photovoltaic energy facilities in California, annual mean and variability
}

\author{
Alberto Boretti ${ }^{1, *}$, Stefania Castelletto $^{2}$, Wael Al-Kouz ${ }^{1}$, Jamal Nayfeh $^{1}$ \\ ${ }^{1}$ Mechanical Engineering Department, College of Engineering, Prince Mohammad Bin Fahd University, Al Khobar, Saudi Arabia \\ ${ }^{2}$ School of Engineering, Royal Melbourne Institute of Technology (RMIT) University, Bundoora, Victoria, Australia
}

\begin{abstract}
The capacity factors of the largest solar photovoltaic (PV) energy facilities of California are computed, based on a low-frequency monthly statistic that is covering the last few years. While the bestperforming facilities achieve annual capacity factors of about $32-33 \%$, the average annual capacity factor is less than $30 \%$, at about $26-27 \%$. The scattered information on costs suggests a cost penalty of $35 \%$ for a capacity factor gain of $10 \%$. Higher frequency data of 1-minute or less for every facility connected to the same grid and the grid average energy supply are needed to define the energy storage indispensable to cover a given demand. The individual facility energy production requires to account for a cost associated with an energy storage allowance to every producer of intermittent and unpredictable electricity, with this amount inversely proportional to the annual average capacity factor and directly proportional to the standard deviation of the high-frequency capacity factors.
\end{abstract}

\section{Introduction}

Solar photovoltaic (PV) is growing rapidly along with its applications in many fields such as desalination, power generation, and Heating, Ventilation, and Air Conditioning (HVAC). Furthermore, lots of research is conducted to investigate the effect of the geographical location as well as the climatic conditions on the performance of such systems [1-5]. Within the US, solar generation is growing significantly, especially in California. There are presently 32 plants of registered capacity of $100 \mathrm{MW}$ and above, see Table 1. The most part is PV, only a very few are solar thermal. The average capacity factor of solar thermal is 0.25 , while the average capacity factor of solar PV is larger at 0.30 .

Because of increasing uptake and the phasing out of back-up conventional power plants producing energy on demand, there is the necessity to study the current variability of the capacity factors based on the actual energy production rather than predicted and extrapolated values based on resources variability. High-frequency energy produced data, ideally every minute or less, is unavailable, as unavailable are the same frequency simultaneous resource data. Only high-frequency data of resources, environment, power plant components, and system may allow a proper validation of models. Understanding the variability is required to design the energy storage needed to compensate for the unpredictable and intermittent solar energy output on the grid. Here we report on monthly average capacity factors from the EIA [6] for some of the individual stations of California, US. What is relevant from grid stability and energy storage design, is the average of all the facilities connected to the same grid but computed with high frequency. Thus, then we present some higher frequency data, with sampling frequency 5 minutes for the daily result, and 3 hours sampling frequency for the monthly result, of all the solar facilities, all PV, connected to the Australian National Electricity Market Grid. This is the higher frequency result available worldwide.

The EIA and the California Energy Commission do not always refer to the same solar station with the same name. Mt. signal 3 by the California Energy Commission and Wikipedia is called Mount Signal V by the EIA. For Panoche Valley the EIA Form 860, as well as the California Energy Commission, report a $240 \mathrm{MW}$ that is incorrect, as the power station has been downgraded. There is a more reasonable figure of $130 \mathrm{MW}$ reported in a local newspaper and Wikipedia that is here used, which may still to some extent be not accurate. What is called Silver Ridge Mount Signal by the California Energy Commission is highly likely Imperial Valley Solar, LLC by the EIA, and Mount Signal 1 by Wikipedia. Antelope Valley 1 is $250 \mathrm{MW}$ for the California Energy Commission, but it is $230 \mathrm{MW}$ for Wikipedia, which also calls the plant Antelope Valley Solar Ranch 1 about the same of the EIA, calling the plant AV Solar Ranch 1.

Different technologies explain different costs and performances. Solar Star is a $579-\mathrm{MW}_{\mathrm{AC}} \mathrm{PV}$ power station completed in 2015, it uses 1.7 million solar panels spread over $13 \mathrm{~km}^{2}$. Compared to other PV plants of similar size, Solar Star uses a smaller number (1.7 million) of large form-factor, high-wattage, highefficiency, higher cost crystalline silicon modules, mounted on single-axis trackers. In contrast to Solar Star, Desert Sunlight is a close capacity $550 \mathrm{MW}_{\mathrm{AC}} \mathrm{PV}$

Corresponding author: a.a.boretti@gmail.com 
power station near to Desert Center, California, uses 8.8 million of smaller form-factor, lower wattage, efficiency, and cost thin-film CdTe PV modules, mounted on fixedtilt arrays and spread over a larger land area of $16 \mathrm{~km}^{2}$. Desert sunlight has capacity factors of 0.28. Solar star has capacity factors of 0.32-0.33.

Table 1 - Solar power plants in California. Energy production data for the year 2018. Data from [7], rectified where needed from [6]. Capacity data from [8]. The table is reproduced modified from [9]. In bold some of the largest PV facilities here discussed.

\begin{tabular}{|c|c|c|c|}
\hline Plant Name & $\begin{array}{c}\text { Power } \\
M W\end{array}$ & $\begin{array}{l}\text { Energy } \\
M W h\end{array}$ & $\begin{array}{l}\text { Capacity } \\
\text { Factor }\end{array}$ \\
\hline \multicolumn{4}{|c|}{ Solar Thermal } \\
\hline Genesis & 250 & 623,189 & 0.28 \\
\hline Ivanpah I & 126 & 242,425 & 0.22 \\
\hline Ivanpah II & 133 & 277,055 & 0.24 \\
\hline Ivanpah III & 133 & 276,327 & 0.24 \\
\hline Mojave & 250 & 604,777 & 0.28 \\
\hline \multicolumn{4}{|c|}{ Solar Photovoltaic } \\
\hline Antelope Valley 1 & 230 & 606235 & 0.30 \\
\hline Blythe Solar 1 & 110 & 298,847 & 0.31 \\
\hline Blythe Solar II & 125 & 345,083 & 0.32 \\
\hline California Flats N & 130 & 361,793 & 0.32 \\
\hline California Valley & 250 & 674,796 & 0.31 \\
\hline Campo Verde & 147.2 & 326,508 & 0.25 \\
\hline Catalina Solar PI,II & 110 & 265,818 & 0.28 \\
\hline Centinela Solar & 174 & 458,800 & 0.30 \\
\hline Desert Stateline & 299 & 667,167 & 0.25 \\
\hline Desert Sunlight 250 & 250 & 619922 & 0.28 \\
\hline Desert Sunlight 300 & 300 & 724920 & 0.28 \\
\hline Garland Solar & 205.1 & 601,730 & 0.33 \\
\hline Great Valley Solar & 200 & 540,441 & 0.31 \\
\hline Henrietta Solar & 102 & 251,373 & 0.28 \\
\hline Imperial Solar South & 128.9 & 274,473 & 0.24 \\
\hline Imperial Solar West & 148.7 & 377,263 & 0.29 \\
\hline Mount Signal 3 & 252.3 & $N A$ & $N A$ \\
\hline Panoche Valley & 140 & 212405 & 0.18 \\
\hline Quinto Solar PV & 108 & 285,687 & 0.30 \\
\hline RE Astoria & 100 & 287,883 & 0.33 \\
\hline Mount Signal 1 & 206 & 493286 & 0.27 \\
\hline Solar Star I & 318 & 906341 & 0.33 \\
\hline Solar Star II & 279 & 790090 & 0.32 \\
\hline Springbok Solar 1 & 105 & 298,337 & 0.32 \\
\hline Springbok Solar 2 & 155 & 407,457 & 0.30 \\
\hline Topaz Solar LLC & 550 & 1335727 & 0.28 \\
\hline Tranquillity LLC & 205.3 & 501,751 & 0.28 \\
\hline
\end{tabular}

Numerical analyses of Solar Star and Desert Sunlight by SAM [10], [11], [12], [13] are proposed in [9]. What is shown, is that there is a mismatch with the solar resource data. The power stations' output shows significant differences from summer to winter. Conversely, the SAM resource is characterized by a small difference between the solar irradiance for the winter compared with the one for the summer. The weather spark data [14] is consistent with the plant data, but extremely far from the SAM resource database. SAM adopts a semi-empirical model for PV plants that need tuning and validation with a high-frequency resource, weather, and plant data to become reliable. This supporting information is unfortunately unavailable.
Regarding the 4 largest stations, these are Topaz, Antelope Valley, Solar Star, and Desert Sunlight. Topaz had Construction began 2011 and Commission date is 2014. Actual construction cost, a parameter hard to be sourced out in renewable energy projects, was 2.4 billion \$US (of 2011). The solar power station is Flat-panel PV (same as the others). Topaz has a Site area of $19 \mathrm{~km}^{2}$ and a nameplate capacity of $550 \mathrm{MW}_{\mathrm{AC}}$. The capacity factor is about $26-27 \%$.

Construction of Solar Star began in 2013 and the facility was commissioned in 2015 . The site area is 13 $\mathrm{km}^{2}$. The nameplate capacity is 579 MWAC. There is no information about the cost. The capacity factor is much larger, at about $33.2 \%$.

Construction of Desert Sunlight began in 2011 and Commission date of 2015 . The site area is $16 \mathrm{~km}^{2}$. The nameplate capacity is $550 \mathrm{MWAC}$. The capacity factor is about $26-27 \%$. There is no publicly available information about the cost.

Construction of Antelope Valley began in 2011 and the facility was commissioned in 2014. The site area is $8.50 \mathrm{~km}^{2}$. The nameplate capacityis $230 \quad \mathrm{MW}_{\mathrm{AC}}$. Capacity factors are higher at about $30 \%$. Construction cost was 1.36 billion \$US (of 2011).

Compared to Topaz, the cost is higher than Topaz, 1.36 billion \$US per $230 \mathrm{MW}$, i.e. 5.91 million \$US/MW, vs. the 2.4 billion \$US per $550 \mathrm{MW}$. i.e. 4.36 million \$US/MW, of Topaz. An 8\% increment of the capacity factor is paid at the price of an increased cost of $35 \%$.

Genesis, an alternative concentrating solar power parabolic trough technology (see Table 1), was constructed between December 2010 and 2014, at a specific cost of 1.25 billion \$US per $250 \mathrm{MW}$, or 5 million \$US/MW. This is an intermediate specific cost vs. Topaz (4.36) and Antelope Valley (5.91), but much closer to the value of Topaz. Genesis has a similarly intermediate capacity factor of 0.28 , about the same of Topaz and slightly less than Antelope Valley that however has a much larger cost.

Hence, the expansion of PV installations compared to CSP parabolic trough because of the lower costs does not seem correct. With a larger solar field per unit power to the turbine, CSP plants with thermal energy storage may deliver further improved capacity factors with the added advantage of the dispatchability. The only problem of thermal energy storage is the maturity of the technology and the definition of an industrial product to mass-produce the same as PV.

\section{Materials and methods}

Data for PV electricity production in the US have been obtained from the US Energy Information Administration (EIA) [6]. The data of [6] is available every month as the net generation in MWh. The monthly capacity factors $\varepsilon$ are computed by diving the monthly electricity production by the product of capacity (power) $\mathrm{P}$ in $\mathrm{MW}$, and the number of hours in a month $\mathrm{n}$. 


\section{Results}

The experimental results of Solar Star and Desert Sunlight were previously analyzed in [15]. Solar Star had an annual average $\varepsilon$ of $33.0 \%$ in $2017,28.5 \%$ in 2016 and $31.9 \%$ in 2015 . Desert Sunlight had an annual average $\varepsilon$ of $27.9 \%$ in 2016 and $26.7 \%$ in 2015 . No data were available for 2017 in [15].

Fig. 1 presents the experimental results for 9 of the facilities of Table 1 (those in bold). These results allow us to understand the differences in the monthly values as well as in the annual values. Start-up is always an issue, with facilities always underperforming in the first year. Mount Signal 1, as well as Desert Sunlight 1 and 2, have annual average capacity factors approaching $0.27-0.28$. Mount Signal 3 recently installed seems to work about
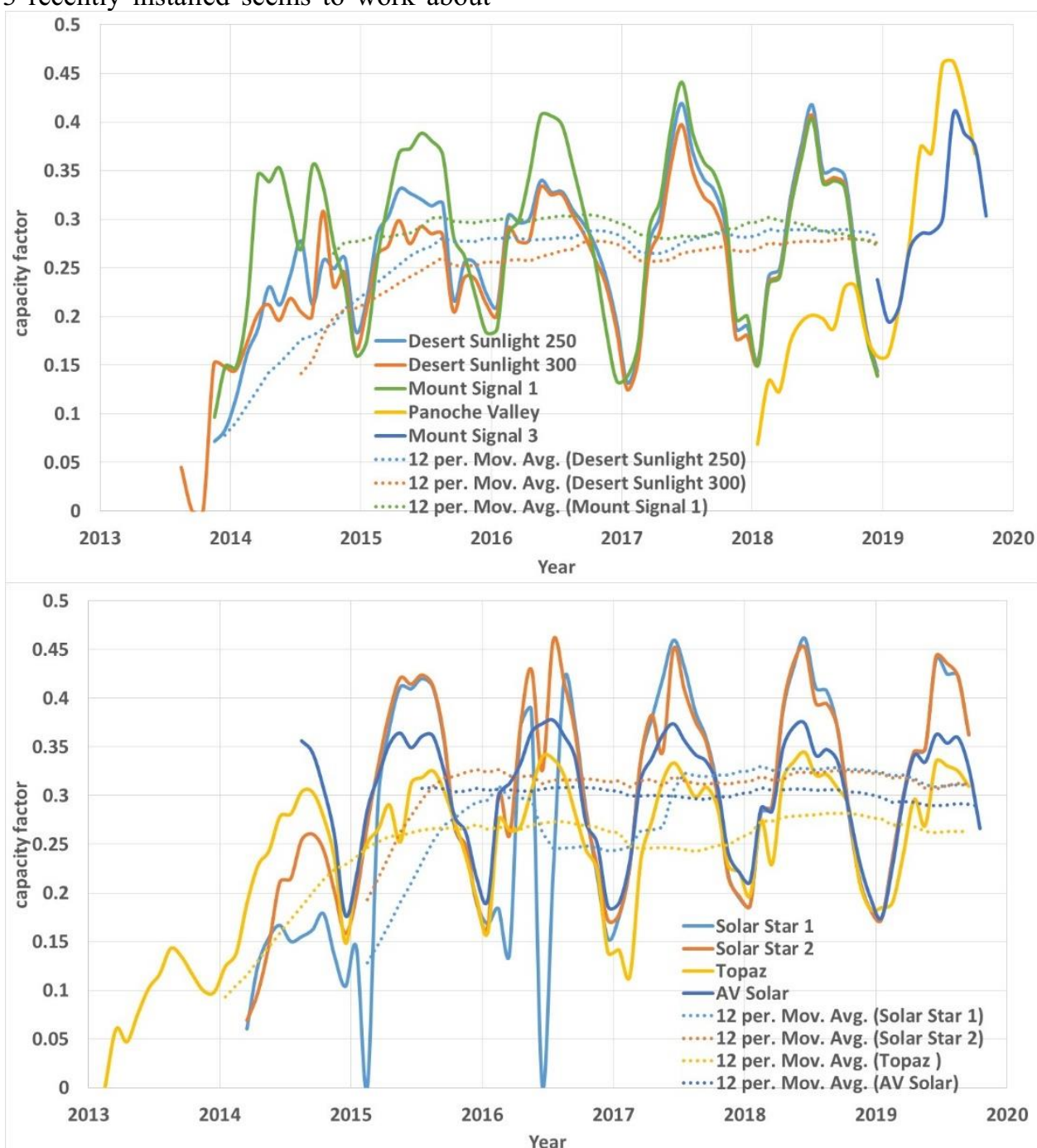

Fig. 1. Measured capacity factors since the completion of 9 in between the largest PV solar energy facilities in California. 12 months moving averages are also shown.

It is important to note the following: the annual average capacity factor experimentally is higher for the most sophisticated design of Solar Star-; there is a relatively large difference between winter minimum and summer maximum capacity factors for all stations. The 12 months moving averages permit to appreciate the improving performances following the troublesome start of production, indicating maturity issues. the same capacity factors in 2019, while however, the data for the other facilities end in December 2018. Panoche Valley has unusual behavior, as this facility was underperforming in 2018 and it is over-performing in 2019. Considering the California Energy Commission is reporting for this facility a nameplate capacity of 240 MW that is incorrect, while the EIA reports $140 \mathrm{MW}$ nameplate capacity in their Form EIA-860 detailed data with previous form data (EIA-860A/860B) [4], these data must be taken with care. Solar Star 1 and 2 are the only stations with capacity factors sustainably above $30 \%$. Antelope Valley had a capacity factor slightly more than $30 \%$ now down turning below $30 \%$. Topaz is lately oscillating between $26-28 \%$. 
factors are 33.91\% (for the more expensive Solar Star COSTs are not given) and $27.59 \%$ (for the less expensive Desert Sunlight COSTs are not given).

Over the year, the experimental capacity factors fluctuate from 0.467 to 0.185 in Solar Star 1 (ratio 2.524 ), and 0.474 to 0.192 in Solar Star 2 (ratio 2.468), while they fluctuate from 0.418 to 0.144 (ratio 2.909) in Desert Sunlight 1, and 0.407 to 0.140 (ratio 2.909) in Desert Sunlight 2. The solar resource is about the same in the two locations.

High-frequency data of resource, weather, and power plant components and system output are necessary to design the energy storage needed to produce a stable grid fed by intermittent and unpredictable wind and solar energy. Similarly, to provide validation of renewable energy software tools, making them accurate and reliable, data must be based on high frequency (every minute or less) accurate weather and plant data, with this latter both at the system, as well as the components level. Validation attempts such as comparison of computed annual electricity production with reports in the media of electricity production for the same plants, such as [16], [17], [18], are by no way a proof that specific renewable energy tools can be used to design new renewable energy facilities properly computing their performances. Regretfully, as per today, 5 minutes' interval capacity factor of energy facilities including renewable is only available for the Australian national electricity market grid, with every other country hiding this information, Fig. 2. December is a midsummer month in Australia. On average, the solar energy facilities of Australia work with capacity factors of $0.27-0.28$. Higher values are obtained during the summer, lower values during the winter, for obvious reasons. The grid average result dictated the properties of the energy storage need to cover the grid demand with the supply by wind and solar. The result for the individual facility permits us to determine the energy storage cost attribution.
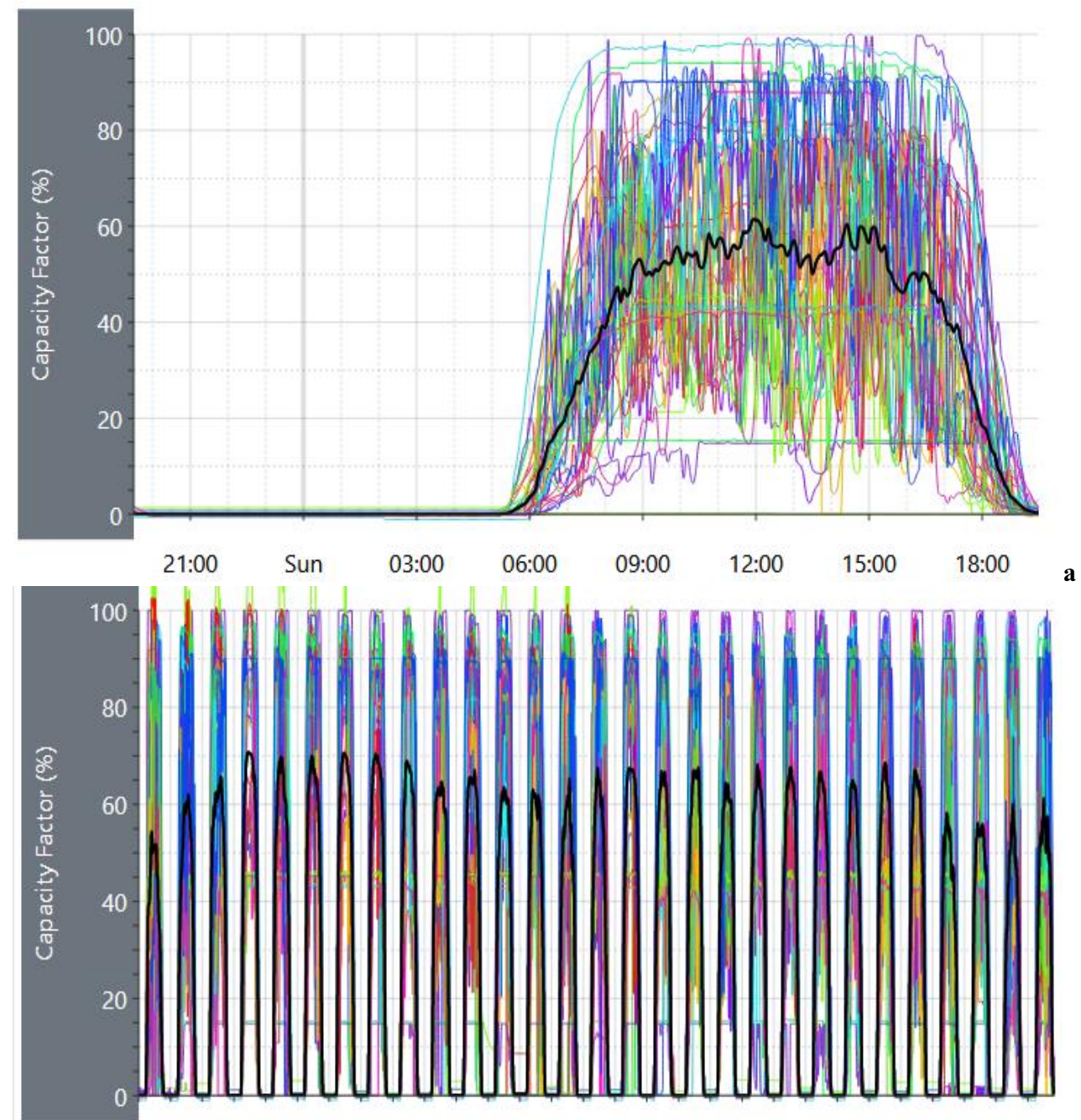

0102030405060708091011121314151617181920212223242526272829 b

Fig. 2. Measured capacity factors of all the PV facilities connected to the Australian National Electricity Market Grid. Image reproduced modified from [19]. (a) December 29, 2019. 5 minutes of resolution. (b) December 2019, 3 hours' resolution, updated to December 29, 2019. The tick black line is the grid average.

The statistic of the capacity factor of the PV solar facility of Broken Hills, NSW, Australia during the year
2018 [15] is a good example of PV variability in an area much better for the weather conditions (no sand and 
dust). The capacity factors oscillate between 0 and 1 . Nighttime is zero. Daytime approaches 1. The mean capacity factor is 0.27 . The standard deviation of the capacity factor is 0.37 . The coefficient of variability is more than unity at 1.37 . In principle, the power in excess than the average must be stored for later release in the energy storage. The power in defect of the average must be released by the energy storage. This has not to be ensured at the plant level, but at the grid level. However, it is expected that plants with a larger coefficient of variability contribute more to the cost of the grid energy storage. Electricity produced when not needed and not produced when needed is a major issue that must be finally accounted for.

\section{Conclusions}

We have shown the monthly capacity factor of some of the latest and largest PV solar power stations in California. In the few cases considered for construction costs, they are still large, at about $5000 \$ / \mathrm{kW}$, same of concentrated solar power parabolic trough. The mean capacity factors are about $29 \%$ on average, a maximum of $33 \%$, but a minimum of $18 \%$. This is slightly better than concentrated solar power stations parabolic trough without energy storage, that work with mean capacity factors about $28 \%$. Higher quality panels and tracking improve performances of a few percents. The highfrequency standard deviation of the capacity factor cannot be assessed, the same as the variability of all the stations when connected to the same grid for lack of data. From the Australian experience, we know the variability is still large at the grid level and needs storage. As energy storage is necessary, for solar PV and wind, the cost of energy storage should be attributed to all the solar PV facilities connected to the same grid and shared inversely proportionally to the annual average capacity factor and directly proportional to a variability parameter, the high-frequency standard deviation of the capacity factor.

\section{Acknowledgments}

The authors did not receive any funds and have no conflict of interest to declare.

\section{Authors contributions}

$\mathrm{AB}$ sourced and analyzed the data and wrote the draft of the manuscript. S.C., W.A., and J.N. discussed the results and contributed to the writing of the final version of the manuscript.

\section{References}

1. British Petroleum (BP), Energy Economics, Statistical Review, Renewable Energy, Solar Energy (2019). www.bp.com/content/dam/bp/businesssites/en/global/corporate/pdfs/energyeconomics/statistical-review/bp-stats-review-2019-fullreport.pdf
2. Almuhtady, A., Alshwawra, A., Alfaouri, M., Al-Kouz, W., \& Al-Hinti, I. (2019). Investigation of the trends of electricity demands in Jordan and its susceptibility to the ambient air temperature towards sustainable electricity generation. Energy, Sustainability, and Society, 9(1), 118.

3. Nader, N., W. Al-Kouz, S. Al-Dahidi. (2019). Assessment of Existing Photovoltaic System with Cooling and Cleaning System: Case Study at Al-Khobar City. Processes, 8(1), 9. doi:10.3390/pr8010009 16.

4. Al-Kouz, W., S. Al-Dahidi, B. Hammad, M. Al-Abed. (2019). Modeling and Analysis Framework for Investigating the Impact of Dust and Temperature on PV Systems' Performance and Optimum Cleaning Frequency. Applied Sciences, 9(7), 1397. doi: 10.3390/app9071397

5. Al-Bashir, A., M. Al-Dweri, A. Al-Ghandoor, B. Hammad, W. Al-Kouz. (2020). Analysis of Effects of Solar Irradiance, Cell Temperature and Wind Speed On Photovoltaic Systems Performance. International Journal of Energy Economics and Policy, 10(1), 353-359. doi:10.32479/ijeep.859

6. Energy Information Administration, Electricity Data Browser - Plant Level Data (2019).

www.eia.gov/electricity/data/browser/

7. California Energy Commission, California Solar Energy Statistics and Data (2019),

www2.energy.ca.gov/almanac/renewables_data/solar/ind ex_cms.php

8. Energy Information Administration (EIA), Form EIA-860 detailed data with previous form data (EIA-860A/860B) (2019). www.eia.gov/electricity/data/eia860/

9. Boretti, A., Nayfeh, J., and Al-Kouz, W., Simulation of large PV energy facilities with SAM HCPV and PV detailed models (2020), ICSREE2020, paper R06.

10. National Renewable Energy Laboratory (NREL), SAM (2019). sam.nrel.gov/

11. Gilman, P., SAM Photovoltaic Model Technical Reference, Technical Report NREL/TP-6A20-64102 (2015). www.nrel.gov/docs/fy15osti/64102.pdf

12. SANDIA, Sandia Inverter Model (2019). pvpmc.sandia.gov/modeling-steps/dc-to-acconversion/sandia-inverter-model/

13. King, D. et al, Performance Model for Grid-Connected Photovoltaic Inverters. Sandia National Laboratories. SAND2007-5036 (2007). infoserve.sandia.gov/sand_doc/2007/075036.pdf.

14. weather spark, The Typical Weather Anywhere on Earth (2019). weatherspark.com/

15. Boretti, A., Cost and Production of Solar Thermal and Solar Photovoltaics Power Plants in the United States, Renewable Energy Focus. 26:93-99 (2018). doi.org/10.1016/j.ref.2018.07.002

16. National Renewable Energy Laboratory (NREL), SAM validation, (2019). sam.nrel.gov/concentrating-solarpower/csp-validation.html

17. National Renewable Energy Laboratory (NREL), System Advisor Model (SAM) Case Study: Andasol-1 Aldeire, Spain (2013).

/sam.nrel.gov/images/web_page_files/sam_case_csp_phy sical_trough_andasol-1_2013-1-15.pdf

18. National Renewable Energy Laboratory (NREL), System Advisor Model (SAM) Case Study: Gemasolar Fuentes De Andalucía, Spain (2013). sam.nrel.gov/images/web_page_files/sam_case_csp_salt tower_gemasolar_2013-1-15.pdf

19. anero.id/energy/solar-energy/ 